Article

\title{
The Construction and Implication of Group Scale Efficiency Evaluation Model for Bulk Shipping Corporations
}

\author{
Bor-Hong Lin, Hsuan-Shih Lee and Cheng-Chi Chung * \\ Department of Shipping and Transportation Management, National Taiwan Ocean University, \\ Keelung City 20224, Taiwan; paulolim@eddieship.com (B.-H.L.); hslee@mail.ntou.edu.tw (H.-S.L.) \\ * Correspondence: jackie@mail.ntou.edu.tw
}

Received: 25 March 2020; Accepted: 20 April 2020; Published: 2 May 2020

check for updates

\begin{abstract}
The shipping industry pursues high efficiency and low cost of chartering operations for bulk shipping market depression. Each type of ship's operational efficiency in bulk shipping corporations is more important than the corporation's overall efficiency. In order to evaluate the efficiency gap between various ship types' efficiency and overall efficiency, the research first assessed the performance by a decision making unit (DMU), and evaluated voyage charter $(\mathrm{V} / \mathrm{C})$ performance by the time charter equivalent (TCE). It also measured the distance between group scale efficiency (GSE) and average group scale efficiency (AGSE) by the data envelopment analysis (DEA). DEA is able to compare the difference between the group efficiency and overall efficiency, the AGSE value, to explore the direction and extent of the overall efficiency improvement. In the research, the $\mathrm{V} / \mathrm{C}$ service of Panamax, Supramax, and Handymax is considered as the DMU, to calculate the efficiency of different ship types separately. Then, it employs TCE to measure and the DEA method to compare AGSE. The larger the AGSE value, the better the efficiency. Based on the results, in order to improve the overall operating efficiency of bulk shipping corporations, AGSE should be more emphasized than TCE and GSE. The results can provide professional managers of bulk shipping corporations with the basis for a strategic decision of chartering operations.
\end{abstract}

Keywords: bulk shipping; voyage charter; time charter equivalent; average group scale efficiency

\section{Introduction}

Except for financial managerial tools by the bareboat charter, there are the time charter $(\mathrm{T} / \mathrm{C})$ and the voyage charter $(\mathrm{V} / \mathrm{C})$ in the chartering business. In $\mathrm{T} / \mathrm{C}$, the charterer gets full use of the vessel, but partial control, for specified period of time. During that time, he operates the vessel for his own account. Meanwhile, in $\mathrm{V} / \mathrm{C}$, a vessel or part of a vessel is leased to a charterer for a voyage between specified ports, regardless the time it takes, and owner retains control and full responsibility for the operations of the vessel. In order to assess the operational performance of bulk shipping corporations, maximizing the time charter equivalent (TCE) and using data envelopment analysis (DEA) are both worthy methods of efficiency analysis. Based on the characteristics of DEA, this research further proposes the average group scale efficiency (AGSE), which is outlined in the subsequent section. In addition, it employs the AGSE to measure the shift of group frontiers against global frontier instead of the meta-frontier concept. Therefore, the efficiency of groups could be reflected by AGSE.

According to Battese and Rao [1], a stochastic meta-frontier model was proposed, and the equivalent technical efficiency (TE) could be estimated through this model. O'Donnell et al. [2] used the concept of meta-frontier to compare the technical efficiency of different groups. However, the result only shows that a single decision making unit (DMU) is inefficient without determining the group efficiency of the DMU to which it belongs. A DMU here in this paper refers to a ship to be evaluated. 
Evaluating operational efficiency is an important reference for the overall or individual ship operating efficiency of bulk shipping corporations. This study uses TCE to evaluate V/C performance and the DEA method to figure out the average group scale efficiency (AGSE) in order to more accurately measure the relationship between the group efficiency and the overall efficiency. First, it employs the technical efficiency values to calculate each GSE, and applies the geometric average to calculate AGSE. The efficiency gap is further explained in order to explore the improvement for bulk shipping corporations.

In the bulk shipping market, the freight rates of Capesize and other very large bulk carriers fluctuate greatly. The level of freight rates is mainly controlled by the markets, and the operating efficiency is easily biased because of the market. Therefore, in order to prove the usability and effectiveness of the model, the research selects the actual operating data of Panamax, Supramax and Handymax. Through evaluating their operating efficiency and exploring their pros and cons of operating efficiency, this could pursue the achievement of the company's overall operating efficiency goals.

This study collects the operating data of the three types of vessel from January 2016 to December 2017 , and extracts the V/C data of each type of vessel for analysis. The first stage is to calculate the TCE of each voyage. The proportion of the first $50 \%$ and the last $50 \%$ of TCE for evaluation are taken. Then, the top 28 voyages with the highest TCE are selected, and the proportion of the 28 voyages to the total voyages of each group are calculated. Secondly, we calculate the group and overall technical efficiency by the DEA method. The overall technical efficiency value is divided by the group technical efficiency value to explore the GSE, as well as the GSE by the overall average efficiency, in order to obtain the AGSE of each ship type. After that, we compare the AGSE of each ship type to find the most efficient one. This paper develops a method to measure the efficiency for a group of DMUs, which is called AGSE. It further evaluates the performance of bulk ships over a period of time by AGSE. Compared to TCE, which is a traditional method used in the bulk shipping industry, AGSE outperforms it. The empirical study shows that AGSE is a promising methodology in the shipping industry.

The research results reveal that the operating efficiency of three types of bulk carrier are based on market structure during the data period, regardless of the type of cargo transported and the route of each type of ship. This is an important decision reference for decision-making managers in bulk shipping corporations to analyze the efficiency of ship operations, to choose the best operational strategy, and to reach chartering decisions. In this research, the second section reviews the literature and discussions, the third section explains the research method, the fourth section conducts empirical analysis and discussions, and final section presents the research conclusions and recommendations.

\section{Literature Review}

This section reviews the literature on performance evaluation and shipping operation performance evaluation, and then presents discussions.

\subsection{Performance Evaluations}

According to the model hypothesis proposed by Battese and Rao [1], there are two different data generation mechanisms; one is about the random frontiers related to the technology of the corporations, and the other is the meta-frontier model. Battese et al. [3] then proposed a modified model, assuming that there were only one data generation process for the enterprise boundary function, including the leading-edge production function of the related technology.

O'Donnell et al. [2] used the concept of presenting the basic analytical framework necessary for the definition of a meta-frontier. The meta-frontier can be estimated by using non-parametric and parametric methods to present an empirical application and the data of cross-country agricultural sector to compare the technical efficiency of different groups of enterprises. Furthermore, it explores the issues of technological change, time-varying technical inefficiency, multiple outputs, different efficiency orientations and firm heterogeneities. The shipping firms in different market segments, such as dry bulk, liquid bulk, and containerized cargo, possibly operate different technologies to obtain relative 
efficiency. Hence, a meta-frontier function approach was applied to estimate operational efficiency and technology gaps for shipping companies under different frontiers [4].

According to Chung and Hwang [5], the DEA method was used to assess the operational performances for five selected public bulk shipping corporations. Inputs and outputs were selected on the concepts of production function, and the window analysis method was adopted to overcome the limitation of small sample sizes. Huang et al. [6] used DEA and window analysis to evaluate the efficiency of major global container carriers and to test the differences in efficiency between strategic groups on the basis of their strategic choices in terms of fleet capacity, asset/debt ratio, owned/chartered-in fleet ratio, non-container revenue ratio and revenue from 2006 to 2011. They examined each DMU by matching individual structural factors for the assessment of efficiency.

According to the research of Gong et al. [7], they illustrated the problem by evaluating the economic and cargo efficiencies of shipping companies both with and without considering the negative impact of emissions and comparing this with their environmental efficiencies. The measured efficiency of these companies, even adjusting for negative environmental impact, is different from environmental efficiency, which is also known as eco-efficiency. Tone and Tsutsui [8] proposed a dynamic DEA model involving analysis under the network structure for each period within a framework based on a slacks-based measure approach. This research applied the model to the dynamic data report analysis method with network structure for the US electric utilities. The overall efficiency of the entire observation period, the change in kinetic energy of cycle efficiency and the change of kinetic energy of individual efficiency can be evaluated.

Lee and Yeh [9] proposed that, in multiple criteria decision-making problems, decision makers often need to select or rank the choices related to non-commensurate and conflicting criteria consisting of benefit and cost criteria. DEA may be used to solve a multiple criteria decision making problem by considering the benefit criteria as outputs and the cost criteria as inputs, so as to propose a fuzzy multiple objective data envelopment analysis model. A modified network DEA model (NDEA) can measure the performance of intermodal freight transport chains, and find the sources of inefficiencies for the chains which may differ in the number of divisions [10].

\subsection{Shipping Operating Performance}

Hwang and Chung [11] evaluated five listed bulk shipping corporations in Taiwan by DEA. They pointed out that the more the ship's deadweight tonnage was, the lower the relative operating efficiency. The possible reason for this is that the companies with large deadweight tonnages in the charterer's market usually reduce the charter hires or ocean freights, resulting in a decrease in shipping revenue, in order to obtain a large and stable supply of goods or increase the opportunity for chartering. Wu et al. [12] developed a two-step solution scheme consisting of a dynamic programming algorithm and a tailored Benders decomposition method to solve the bulk ship scheduling in industrial shipping with stochastic backhaul canvassing demand effectively. Then, it conducted extensive numerical experiments to demonstrate that the proposed solution method can well solve the considered problem in various and practical sizes.

Abdul Rahman et al. [13] evaluated the most significant delay factors that are caused in dry bulk cargo operation by the analytical hierarchy process (AHP) method. The result indicates that the factor of "Miscellaneous" is the most significant factor that contributed to the most of delay creations in dry bulk cargo operation in Kemaman port. Lin and Liu [14] considered the ship routing problem of tramp shipping (SRPTP) and proposed a combined mathematical model that simultaneously took into account the problems of SRPTP. The empirical studies demonstrated the applicability of the proposed solution scheme for solving real-world problems that were beyond the reach of a widely used commercial optimization package.

Based on Panayides et al. [15], the relative efficiency of dry bulk, tanker, and container shipping corporations was studied, and two relative efficiency models were developed to evaluate the relative market and operating performance. By DEA and stochastic frontier analysis, it was found that the 
average market efficiency and shipping market and operating performance of shipping corporations are not consistent. Among the enterprises, the oil tanker corporations have the highest market efficiency. The container shipping corporations have high operating efficiency but low market efficiency, while the dry bulk shipping corporations have the lowest market efficiency. Chen et al. [16] studied the efficiency evaluation by DEA for the customer relationship management in the shipping industry. To maintain a highly competitive advantage, price differentiation, concentration strategies, and low shipping expenses could attract new customers, consolidate old customers, and satisfy customer needs with professional knowledge to reinforce customer relationship management.

According to Zaharan et al. [17], they evaluated the efficiency of the port authority in generating revenues by the DEA. This research focused on the efficiency comparison of the income generation mechanism based on the position of the port authorities. The basic concept is that the larger the port throughput, the higher its economic value, and the more assets it generates, the higher the income becomes. With regard to the operating level and resources, ports that generate higher income are considered more efficient. Venturini et al. [18] introduced a novel mathematical formulation that extended the classical berth allocation problem (BAP) to cover multiple ports in a shipping network under the assumption of strong cooperation between shipping lines and terminals. The implementation of the model showed that an accurate speed discretization can result in far better economic and environmental results.

\subsection{Comprehensive Commentary}

The previous related literature mainly focused on the improvement of research methods and the assessment of overall and group efficiency gaps. These studies could only present the technical efficiency and technical gap of each DMU under different technologies. According to the study of O'Donnell et al. [2], only some DMUs are known to be inefficient, but not which groups are inefficient. Moreover, the AGSE that can assess the overall effect of group efficiency has never been taken into account.

In order to solve the problem regarding whether Panamax, Supramax, or Handymax effects overall efficiency, this study uses the actual operating data of ships to verify the TCE of bulk shipping corporations, and compared the AGSE to obtain effective outcomes. The empirical study showed that AGSE is a promising methodology in the shipping industry. The results can be served as the ship operation decisions by senior managers of bulk shipping corporations.

\section{The Methods}

The relationship between the freight rates of voyage charters and the charter hires of time charters is of great relevance. The evaluation of the operating performance of bulk shipping corporations should focus on overall efficiency. In shipping practices, it is mainly based on the various data obtained by the $\mathrm{V} / \mathrm{C}$ to calculate the equivalent of the individual V/C of the ship; that is, the TCE is used to evaluate V/C performance. The larger the TCE obtained, the better the performance is. However, the impact of the efficiency of each ship type on the overall operating efficiency has not been valued. The average scale efficiency of the groups of different ship types has not been evaluated either.

This section introduces the selection of the input and output of performance evaluation, discusses the TCE, DEA model and AGSE model, and finally proposes discussions.

\subsection{The Inputs and Outputs}

Shipping corporations provide shipping services to pursue freight revenues, so the output items are chosen to benefit from a single voyage shipment, i.e., shipping freight revenues minus various charges and fees including brokerages and demurrage, etc. The inputs are the most important influencing factors of ship operations, including (1) voyage operation days: the total number of operation days of each $\mathrm{V} / \mathrm{C}$, (2) cargo tonnages: the number of cargo tonnages directly affecting freight revenues and (3) navigation distance of the ship: the navigation distance for each voyage shipment. 
Hence, the functional relationship between the outputs and inputs of bulk shipping corporations could be expressed as follows:

$$
R=f(D, W, D i s)
$$

where

$R$ represents the single voyage charter profits;

$D$ indicates the number of operating days of each voyage charter;

$W$ indicates the cargo tonnage of each ship loaded;

Dis represents the navigation distance of each voyage shipment.

Shipping corporations provide sea transportation services to gain freight revenues. The operating incomes are limited by deadweights and sailing days. The number of cargoes is limited by the ship's draught and cargo hold capacity. It is usually charged ocean freight rates by deadweights when the shipowner concludes a $\mathrm{V} / \mathrm{C}$ contract with charterers. The shipowner is also subject to the conditions of the vessel, port and dock while pursuing the maximum loading quantities. Single voyage distance not only affects the number of operating days but also increases the variable costs. Therefore, this research selected "the number of operating days, the tonnage of loaded cargos, and the investment of the voyage distance" as the input items. On the other hand, the "single voyage profit" was chosen as the output item. It means that the freight revenues minus the cost of $\mathrm{V} / \mathrm{C}$ shipments, and settle the demurrage or despatch money after the voyage accomplished.

\subsection{The Ship Efficiency of TCE and DEA Method}

The research screened input and output items from a practical point of view. First, the TCE was used as the first stage of performance analysis. In practice, the $\mathrm{V} / \mathrm{C}$ performance was evaluated in order to explore the TCE of each voyage shipment. In the top 50\% ranking, the larger the proportions of DMU for each type of ship, the better the performance of that type of ship.

In the second stage, software was used to perform efficiency analysis, to explore the technical efficiency of each group and the overall technical efficiency, and to perform each group technical efficiency and overall technical efficiency performance. Next, the research analyzed how the operating efficiency performance of each group affected the overall operating efficiency through calculating the AGSE by geometric average method. The largest is 1 , and the smallest is close to 0 but not equal to 0 (this number is set to $\varepsilon, \varepsilon$ is a very small positive value, which is called Non-Archimedean small quantity by Charnes et al. [19], the actual application is always $10^{-4}$ or $10^{-6}$, it means that any factor cannot be ignored). The higher the number, the closer it is to the group scale efficiency, indicating that the AGSE is better. Lastly, the research compared the TCE results with the DEA's to know which one is more efficient.

\subsection{Average Scale Efficiency Model}

Charnes et al. [19] used the production frontier to measure the concept of technical efficiency (TE). Färe et al. [20] adopted a linear programming method for indicating the use of resources, and put forward the concept of total factor productivity in economics. Linear programming was used to explore the frontier of the boundary to evaluate cost efficiency (CE), technical efficiency, and allocative efficiency (AE). The group scale efficiency and the average scale efficiency of each group are shown in Figure 1.

This study employed the DEA software DEAP (Version 2.1, The University of Queensland, Australia) to calculate the overall technology efficiency of each ship against the global frontier. The group technology efficiency of each ship against the group frontier was also calculated by DEAP. Then, it evaluated the performances of different groups of ships by the AGSE methodology described in Section 4.3. 


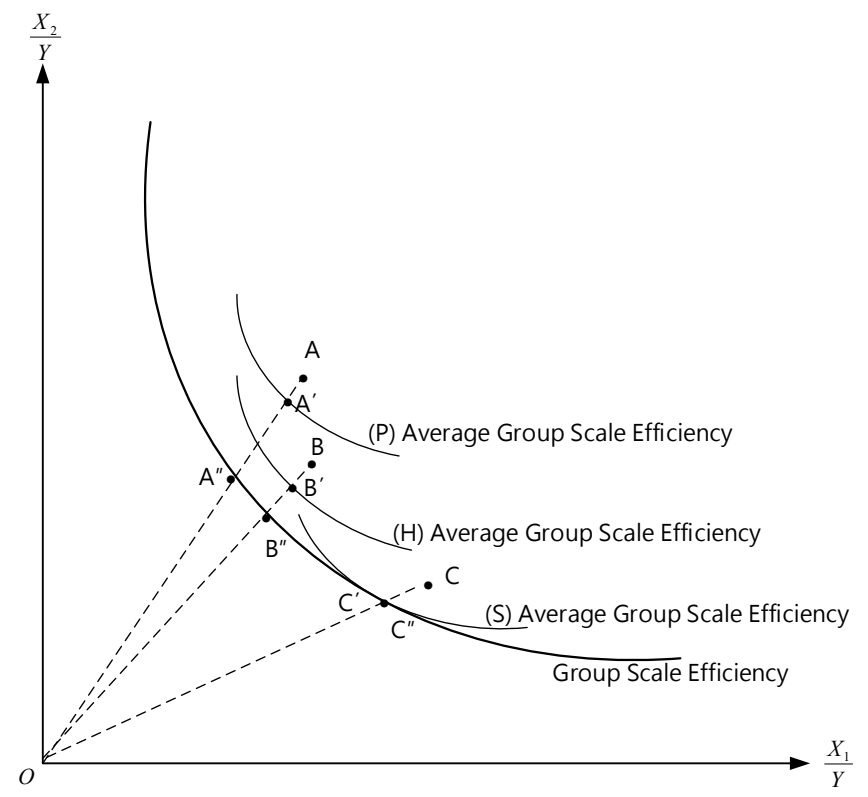

Figure 1. Group scale efficiency and average scale efficiency of each group.

\subsection{Comprehensive Discussions}

This research evaluates the performance of V/C in practical terms to explore the TCE of each voyage shipment. First, the larger the proportions of DMU for each type of ship, the better the performance of that type of ship. Secondly, it regards the 'voyage operating days, loaded cargos, and the vessel voyage distance' as the input item and the 'single voyage profit' as the output item. The DEA method is used to analyze the operating efficiency of bulk Panamax, Supramax and Handymax, and the DMUs. Then, it calculates the GSE based on different ship types to explore the GASE and further find the gap between group frontier and meta-frontier. This method could verify which type of vessel is relatively beneficial to shipping corporations, which is an important issue for assessed $\mathrm{V} / \mathrm{C}$ performance for the proportion of each ship-type DMU.

The way to evaluate the performance of voyages is to take the TCE as an important consideration. The greater the proportion of DMUs for each type of ship, indicating that type of ship had a more effective method, but it could not accurately assess which one is more efficient. Using the DEA method could further confirm that increasing the GE or the AGSE can to improve the overall efficiency, meaning that the overall efficiency depends on the GE and AGSE. To sum up, in order to improve the overall operating efficiency, bulk shipping companies should improve the AGSE of Panamax and Supramax or increase the number of operating vessels of Supramax or only reduce the number of Panamax and Handymax.

\section{The Operational Efficiency Analysis of Shipowners}

This section sorts and evaluates the DMU and TCE, and then explains the AGSE evaluation and discussions.

\subsection{The DMU and Input-Output Items}

Based on the consideration of research completeness and data availability, the research uses three input items and single output item to explore efficiency with an input-oriented focus. It analyzes and compares the output at a given input level by the DMU, explains the group efficiency of each ship type according to the results, and then evaluates its pros and cons. In addition, the research object is the well-known bulk shipping company, E company, which used its actual operating data of different ship types from 2016 to 2017 as the DMU. The data of inputs and outputs of the DMU of the bulk shipping 
company are shown in Appendix A Table A1. This study analyzes the actual operation data of the V/C shipments, including 23 voyages of the Panamax, 15 voyages of the Supramax, and 19 voyages of the Handymax, providing 57 voyages in total as the DMUs.

\subsection{The TCE of Ship of Row Sequence}

Based on the consideration of the maximum revenue, this research uses TCE to further measure the voyage revenue of DMUs. Ship row sequence and accounted ratio of TCE for bulk shipping corporations are shown in Appendix A Table A2.

Based on the TCE in the total sample of 57 voyage shipments, there are 12 voyages of 15 Supramax, which accounts for $21.05 \%$ of the top 50\% of the overall TCE; similarly, Panamax accounts for $15.79 \%$, and Handymax accounts for $12.28 \%$.

There are different markets for distinct ship types. Since it is not possible to compare the performance of each other, the research considers TCE and DEA evaluation to estimate AGSE.

In general, bulk shipping corporations only use TCE to evaluate V/C performance; that is, the voyage revenues are converted to actual daily hire to measure. However, each type of ship has a varied market, and the charter hire rates of market may be dissimilar. TCE cannot be used to compare per ship per voyage. Hence, the research employs TCE and DEA to calculate the AGSE for evaluations.

\subsection{Average Group Scale Efficiency}

Charnes et al. [19] proposed the following CCR model in the multiplier form to evaluate the performance of a decision making unit (DMU):

$$
\begin{aligned}
& \max \sum_{r=1}^{s} u_{r} y_{r k} \\
& \text { s.t. } \sum_{i=1}^{m} v_{i} x_{i k}=1 \\
& \sum_{r=1}^{s} u_{r} y_{r j}-\sum_{i=1}^{m} v_{i} x_{i j} \leq 0, j=1, \ldots, n \\
& u_{r} \geq 0, r=1, \ldots, s \\
& v_{i} \geq 0, i=1, \ldots, m
\end{aligned}
$$

in which $x_{i j}$ and $y_{r j}$ denote the $i$ th input and $r$ th output of DMU $j$. The dual of (2) is:

$$
\begin{aligned}
& \min \theta \\
& \text { s.t. } \\
& \theta x_{i k}-\sum_{j=1}^{n} \lambda_{j} x_{i j} \geq 0, i=1, \ldots, m \\
& \sum_{j=1}^{n} \lambda_{j} y_{r j} \geq y_{r k} 0, j=1, \ldots, n \\
& \lambda_{j} \geq 0, j=1, \ldots, n
\end{aligned}
$$

Model (1) and (2) are used to evaluate the performance of a target DMU. To evaluate the performance of a subgroup of DMUs, the following method is purposed.

Assume that there are $G$ groups of DMUs with $m$ inputs and $s$ outputs. Let $x_{i j}^{g}$ and $y_{r j}^{g}$ denote the $i$ th input and $r$ th output of DMU $j$ in group $g$ respectively, where $i=1, \ldots, m, r=1, \ldots, s$ and $j=1, \ldots, n_{g}$. Let $n$ be the number of all DMUs, $n=\sum_{g=1}^{G} n_{g}$. Then the production possibility set for group $g$ under constant returns to scale is

$$
P_{g}=\left\{\left(x_{i}, y_{r}\right) \mid x_{i} \geq \sum_{j=1}^{n_{g}} \lambda_{j} x_{i j^{\prime}}^{g}, y_{r} \leq \sum_{j=1}^{n_{g}} \lambda_{j} y_{r j^{\prime}}^{g}, i=1, \ldots, m, r=1, \ldots, s\right\} .
$$


The production possibility set for all DMUs under constant returns to scale is

$$
P=\left\{\left(x_{i}, y_{r}\right) \mid x_{i} \geq \sum_{g=1}^{G}\left(\sum_{j=1}^{n_{g}} \lambda_{j} x_{i j}^{g}\right), y_{r} \leq \sum_{g=1}^{G}\left(\sum_{j=1}^{n_{g}} \lambda_{j} y_{r j}^{g}\right), i=1, \ldots, m, r=1, \ldots, s\right\} .
$$

Let $\alpha_{k}^{g}$ denote the group technology efficiency of DMU $k$ in group $g$ with respect to technology $P_{g} ; \beta_{k}^{g}$ denotes the overall technology efficiency of DMU $k$ in group $g$ with respect to technology $P$. Input-oriented $\alpha_{k}^{g}$ could be obtained from the following model:

$$
\begin{aligned}
& \alpha_{k}^{g}=\min \theta \\
& \text { s.t. }\left(\theta x_{i k^{\prime}}^{g} y_{r k}^{g}\right) \in P_{g}
\end{aligned}
$$

Input-oriented $\beta_{k}^{g}$ could be obtained from the following model:

$$
\begin{aligned}
& \beta_{k}^{g}=\min \theta \\
& \text { s.t. }\left(\theta x_{i k^{\prime}}^{g}, y_{r k}^{g}\right) \in P
\end{aligned}
$$

The group scale efficiency for DMU $k$ in group $g$ is defined as

$$
S E_{k}^{g}=\frac{\beta_{k}^{g}}{\alpha_{k}^{g}}
$$

The average group scale efficiency for group $g$ is given by

$$
e_{g}=\sum_{k=1}^{n_{g}} \frac{\beta_{k}^{g}}{\alpha_{k}^{g}}=\sum_{k=1}^{n_{g}} S E_{k}^{g}
$$

$e_{g}$ could be employed as a performance index for group $g$, by which groups could be compared and ranked accordingly.

This research uses the DMUs to calculate the basic efficiency values, including group technical efficiency, average group efficiency, overall technical efficiency, overall average efficiency, group scale efficiency and average group scale efficiency. Group and overall efficiency values of the bulk shipping corporations are shown in Appendix A Table A3.

After applying Equations (3)-(6) to Appendix A Table A1, the results are ranked in Appendix A Table A3. In terms of technical efficiency, the overall average efficiency is 0.421 and the group average efficiency of Panamax, Supramax and Handymax are 0.566, 0.522, and 0.698, respectively. The average technical efficiency of each group of the three ship types is greater than the overall average technical efficiency. We could not determine which group was affected by the overall average efficiency and the degree of the impact. Hence, the research further calculates the AGSE for the Panamax type, Supramax type and Handymax type which are $0.59717,1$, and 0.63398 , respectively. In other words, the GSE and AGSE of Supramax are the closest, and the efficiency value of 1 indicates complete overlap, which means that Supramax is better than Panamax and Handymax.

\subsection{Discussion}

The efficiency of a single voyage is evaluated by TCE. The results differ due to the influence of different market conditions. If the ship types are compared at different levels, sometimes their efficiency may not reflect the entire market. At this point, DEA can judge and evaluate the efficiency accurately can be used for judged and evaluated accurately by the DEA; thus the strategic decisions can be made correctly. 
This research is measured by the TCE. It can be known from Appendix A Table A2 that out of the total sample (57 voyage shipments), Supramax has 12 voyages in the top $50 \%$, accounting for $80 \%$ of its group, and its TCE is $21.05 \%$ of the top $50 \%$. Of the 23 voyages of Panamax, only nine voyages are on the list, accounting for $39.13 \%$ of the group but $15.79 \%$ of the overall top $50 \%$. Among the 19 voyages of the Handymax group, seven voyages are listed, accounting for $36.84 \%$ of the group and only $12.28 \%$ of the top $50 \%$. It could be seen that, in terms of TCE ratio, Supramax's ship efficiency at all levels is significantly superior to Panamax and Handymax.

By the DEA method and technical efficiency, it can be seen from Appendix A Table A3 that the overall average efficiency is 0.421 , and the average efficiency of Panamax, Supramax and Handymax are $0.566,0.522$, and 0.698 , respectively. It is obvious that the GSE of these three ship types is greater than the overall average efficiency, but the reason why the overall average efficiency is inefficient could not be determined. The research further calculates the AGSE. The data show that the efficiencies of Panamax, Supramax and Handymax are 0.59717, 1, and 0.63398, respectively. Therefore, it could be known that Supramax is the benchmark for Panamax and Handymax, and Handymax is superior to the efficiency of Panamax.

Traditionally, the efficiency comparison of ships was based on TCE with no scientific method of evaluation. This research uses the DEA method to calculate AGSE. The results indicate that the efficiency of Supramax is the best, whether assessed by TCE or AGSE.

\section{Conclusions and Suggestions}

Based on the above analysis, the main results and suggestions are as follows.

1. The three types of vessel were operated by bulk shipping corporations under the market condition from January 2016 to December 2017. The overall efficiency of bulk shipping corporations is not sufficient enough to determine the operating performance of the vessel type, regardless of the type of cargo, loaded cargos or the voyage operating route. On the other hand, the AGSE is better than the overall average efficiency, but it cannot adjust the single factor to make the overall efficiency best. Therefore, the goal of increasing the overall operational efficiency of bulk shipping corporations can be achieved by improving the AGSE of different ship types.

2. In the data period of the global bulk shipping market, empirical studies have found that in terms of AGSE, Supramax is better than Handymax, and Handymax is better than Panamax. As far as the chartering decision is concerned, if the tonnage cannot be increased or decreased in the short-term, the AGSE of Handymax and Panamax can be actively improved; in the long-term, if the overall efficiency of the company is to be enhanced, it can purchase Supramax or take Supramax on charter, or reduce the investment in Handymax and Panamax.

3. This research suggests that corporations can carry out market dynamics evaluations in order to grasp the drastic changes in the bulk shipping market, add other ship types in bulk carriers so as to compare different ship types, or adopt different inputs and outputs for further exploration of the relationship between different variables.

4. This study collects the actual data of three bulk ship types from 2016 to 2017. Despite the limitation of data availability and the cyclical nature of shipping market, the model constructed can apply to the decision-making process of bulk carriers by rolling-evaluation. In addition, since it is focused on the efficiency of Panamax, Supramax and Handymax in V/C, the ratio of operating T/C and $\mathrm{V} / \mathrm{C}$ contracts could be further discussed. The different considerations of shipping company, including the draft problem, cargo characteristics, equipped with cranes or not, and hold and hatch types, may also be taken into account in future research. Moreover, considering port cargo loading times, subsequent direction may extend to the operations in dry bulk terminals [21], and the allocation in container terminals [22].

Author Contributions: Investigation, B.-H.L.; Methodology, H.-S.L.; Conceptualization, C.-C.C. All authors have read and agreed to the published version of the manuscript. 
Funding: This research was funded by the Ministry of Science and Technology, Taiwan; grant number MOST108-2410-H-019-021. And the APC was funded by the Ministry of Science and Technology, Taiwan.

Conflicts of Interest: The authors declare no conflict of interest.

\section{Appendix A}

Table A1. Shipowner decision making unit (DMU) input items and output items.

\begin{tabular}{|c|c|c|c|c|}
\hline DMUs & $\begin{array}{l}\text { Voyage Profits } \\
\text { (Thousand Dollars) }\end{array}$ & $\begin{array}{l}\text { Voyage Days } \\
\text { (Days) }\end{array}$ & $\begin{array}{l}\text { Cargo Tonnage Loaded } \\
\text { (Thousand Tons) }\end{array}$ & $\begin{array}{l}\text { Voyage Distance } \\
\text { (Miles) }\end{array}$ \\
\hline P-1 & 59.90 & 24.23 & 76.65 & 2760 \\
\hline P-2 & 61.38 & 22.55 & 76.70 & 3082 \\
\hline P-3 & 64.52 & 21.00 & 77.00 & 2825 \\
\hline P-4 & 58.38 & 22.93 & 77.05 & 3200 \\
\hline P-5 & 119.15 & 32.90 & 77.10 & 3190 \\
\hline P-6 & 83.35 & 16.64 & 77.40 & 2978 \\
\hline P-7 & 107.62 & 22.44 & 77.05 & 3166 \\
\hline P-8 & 90.55 & 20.32 & 77.40 & 3059 \\
\hline P-9 & 90.39 & 21.52 & 77.40 & 2708 \\
\hline P-10 & 89.45 & 16.04 & 77.25 & 2839 \\
\hline P-11 & 76.85 & 16.00 & 75.65 & 2791 \\
\hline P-12 & 85.68 & 19.57 & 76.05 & 2651 \\
\hline P-13 & 93.49 & 37.53 & 76.45 & 3180 \\
\hline P-14 & 112.11 & 18.41 & 76.85 & 2695 \\
\hline P-15 & 148.01 & 26.75 & 77.10 & 2574 \\
\hline P-16 & 74.93 & 18.22 & 77.10 & 3054 \\
\hline P-17 & 158.24 & 20.99 & 77.10 & 3054 \\
\hline P-18 & 167.91 & 23.80 & 77.10 & 3066 \\
\hline P-19 & 75.75 & 19.33 & 77.00 & 2788 \\
\hline P-20 & 113.32 & 22.42 & 77.40 & 3060 \\
\hline P-21 & 175.36 & 26.21 & 77.40 & 3310 \\
\hline P-22 & 169.43 & 24.98 & 77.15 & 2787 \\
\hline P-23 & 216.48 & 24.23 & 77.30 & 2772 \\
\hline S-1 & 68.02 & 16.04 & 55.71 & 1327 \\
\hline S-2 & 116.58 & 23.79 & 55.00 & 2614 \\
\hline S-3 & 81.97 & 16.25 & 56.97 & 1419 \\
\hline S-4 & 132.15 & 28.52 & 55.00 & 3047 \\
\hline S-5 & 140.26 & 22.92 & 55.00 & 3424 \\
\hline S-6 & 147.35 & 29.65 & 57.10 & 1589 \\
\hline S-7 & 225.40 & 22.10 & 54.52 & 2981 \\
\hline S-8 & 103.00 & 17.12 & 55.00 & 2609 \\
\hline S-9 & 125.26 & 24.33 & 55.20 & 3500 \\
\hline S-10 & 168.24 & 27.98 & 55.00 & 2948 \\
\hline S-11 & 92.12 & 16.55 & 43.41 & 1655 \\
\hline S-12 & 350.93 & 42.94 & 55.00 & 1777 \\
\hline S-13 & 394.15 & 27.14 & 55.00 & 3015 \\
\hline S-14 & 130.78 & 25.41 & 52.13 & 3737 \\
\hline S-15 & 292.11 & 40.22 & 53.40 & 4304 \\
\hline $\mathrm{H}-1$ & 45.63 & 12.59 & 23.74 & 693 \\
\hline H-2 & 45.93 & 17.56 & 15.12 & 2476 \\
\hline H-3 & 82.69 & 17.60 & 31.55 & 1940 \\
\hline H-4 & 68.46 & 27.66 & 31.26 & 954 \\
\hline H-5 & 103.38 & 24.58 & 31.50 & 3180 \\
\hline H-6 & 85.49 & 16.83 & 31.58 & 1907 \\
\hline H-7 & 114.80 & 24.70 & 30.59 & 2692 \\
\hline H-8 & 89.04 & 17.49 & 31.60 & 1896 \\
\hline H-9 & 86.18 & 21.16 & 31.60 & 2745 \\
\hline H-10 & 93.74 & 17.56 & 31.60 & 2033 \\
\hline H-11 & 102.28 & 39.71 & 31.54 & 2897 \\
\hline H-12 & 43.28 & 11.12 & 25.55 & 1437 \\
\hline H-13 & 124.05 & 20.50 & 31.75 & 2788 \\
\hline H-14 & 94.59 & 17.94 & 31.50 & 2269 \\
\hline H-15 & 94.26 & 20.00 & 31.60 & 1972 \\
\hline H-16 & 129.59 & 23.74 & 31.63 & 2751 \\
\hline H-17 & 115.71 & 19.52 & 31.60 & 2021 \\
\hline H-18 & 174.98 & 20.86 & 30.11 & 2756 \\
\hline H-19 & 55.08 & 19.53 & 24.10 & 2007 \\
\hline
\end{tabular}


Table A2. Ship row sequence and accounting ratio of time charter equivalent (TCE) for bulk shipping corporations.

\begin{tabular}{|c|c|c|c|c|c|}
\hline \multirow{2}{*}{ DMUs } & \multirow{2}{*}{ TCE (Thousand Dollars) } & \multicolumn{2}{|c|}{ Row Sequence } & \multicolumn{2}{|c|}{ Accounting Ratio } \\
\hline & & Top $50 \%$ & After $50 \%$ & Top $50 \%$ & After $\mathbf{5 0 \%}$ \\
\hline P-1 & 3.42 & & 46 & & \\
\hline P-2 & 2.19 & & 56 & & \\
\hline $\mathrm{P}-3$ & 3.38 & & 47 & & \\
\hline P-4 & 2.95 & & 49 & & \\
\hline P-5 & 5.00 & 25 & & & \\
\hline P-6 & 4.22 & & 41 & & \\
\hline P-7 & 5.38 & 19 & & & \\
\hline P-8 & 4.08 & & 42 & & \\
\hline P-9 & 4.25 & & 39 & & \\
\hline P-10 & 4.83 & & 29 & & \\
\hline P-11 & 4.26 & & 38 & & \\
\hline P-12 & 4.22 & & 40 & $15.79 \%$ & $24.56 \%$ \\
\hline P-13 & 2.22 & & 55 & & \\
\hline P-14 & 5.24 & 21 & & & \\
\hline P-15 & 6.26 & 13 & & & \\
\hline P-16 & 2.39 & & 54 & & \\
\hline P-17 & 6.79 & 10 & & & \\
\hline P-18 & 6.67 & 11 & & & \\
\hline P-19 & 3.63 & & 45 & & \\
\hline P-20 & 4.46 & & 35 & & \\
\hline P-21 & 8.34 & 7 & & & \\
\hline P-22 & 8.29 & 8 & & & \\
\hline $\mathrm{P}-23$ & 9.18 & 5 & & & \\
\hline S-1 & 4.03 & & 43 & & \\
\hline $\mathrm{S}-2$ & 4.96 & 26 & & & \\
\hline $\mathrm{S}-3$ & 5.33 & 20 & & & \\
\hline S-4 & 4.94 & 28 & & & \\
\hline S-5 & 6.02 & 14 & & & \\
\hline S-6 & 6.31 & 12 & & & \\
\hline S-7 & 9.96 & 3 & & & \\
\hline S-8 & 4.30 & & 37 & $21.05 \%$ & $5.26 \%$ \\
\hline S-9 & 5.74 & 16 & & & \\
\hline S-10 & 7.18 & 9 & & & \\
\hline S-11 & 5.54 & 18 & & & \\
\hline $\mathrm{S}-12$ & 10.12 & 2 & & & \\
\hline S-13 & 17.38 & 1 & & & \\
\hline S-14 & 4.73 & & 32 & & \\
\hline S-15 & 9.28 & 4 & & & \\
\hline H-1 & 2.95 & & 50 & & \\
\hline $\mathrm{H}-2$ & 2.46 & & 53 & & \\
\hline $\mathrm{H}-3$ & 4.56 & & 33 & & \\
\hline $\mathrm{H}-4$ & 1.31 & & 57 & & \\
\hline H-5 & 4.42 & & 36 & & \\
\hline H-6 & 4.77 & & 31 & & \\
\hline H-7 & 5.23 & 22 & & & \\
\hline H-8 & 4.83 & & 30 & & \\
\hline H-9 & 3.81 & & 44 & & \\
\hline H-10 & 5.20 & 24 & & $12.28 \%$ & $21.05 \%$ \\
\hline H-11 & 2.60 & & 52 & & \\
\hline H-12 & 3.07 & & 48 & & \\
\hline H-13 & 5.60 & 17 & & & \\
\hline H-14 & 4.96 & 27 & & & \\
\hline H-15 & 4.51 & & 34 & & \\
\hline H-16 & 5.21 & 23 & & & \\
\hline H-17 & 5.87 & 15 & & & \\
\hline H-18 & 9.05 & 6 & & & \\
\hline H-19 & 2.68 & & 51 & & \\
\hline
\end{tabular}


Table A3. Bulk overall shipping group each item efficiency value.

\begin{tabular}{|c|c|c|c|c|c|c|}
\hline DMUs & $\begin{array}{l}\text { Group } \\
\text { Technology } \\
\text { Efficiency }\end{array}$ & $\begin{array}{c}\text { Group } \\
\text { Average } \\
\text { Efficiency }\end{array}$ & $\begin{array}{c}\text { Overall } \\
\text { Technology } \\
\text { Efficiency }\end{array}$ & $\begin{array}{c}\text { Overall } \\
\text { Average } \\
\text { Efficiency }\end{array}$ & $\begin{array}{l}\text { Group Scale } \\
\text { Efficiency }\end{array}$ & $\begin{array}{c}\text { Average } \\
\text { Group Scale } \\
\text { Efficiency }\end{array}$ \\
\hline P-1 & 0.279 & \multirow{23}{*}{0.566} & 0.170 & & 0.60932 & \multirow{23}{*}{0.59717} \\
\hline P-2 & 0.305 & & 0.187 & & 0.61311 & \\
\hline P-3 & 0.344 & & 0.212 & & 0.61628 & \\
\hline $\mathrm{P}-4$ & 0.285 & & 0.175 & & 0.61404 & \\
\hline P-5 & 0.552 & & 0.274 & & 0.49638 & \\
\hline P-6 & 0.561 & & 0.345 & & 0.61497 & \\
\hline P-7 & 0.537 & & 0.330 & & 0.61453 & \\
\hline P-8 & 0.499 & & 0.307 & & 0.61523 & \\
\hline P-9 & 0.470 & & 0.289 & & 0.61489 & \\
\hline P-10 & 0.624 & & 0.384 & & 0.61538 & \\
\hline P-11 & 0.538 & & 0.331 & & 0.61524 & \\
\hline P-12 & 0.490 & & 0.301 & & 0.61429 & \\
\hline P-13 & 0.437 & & 0.206 & & 0.47140 & \\
\hline P-14 & 0.682 & & 0.419 & & 0.61437 & \\
\hline P-15 & 0.736 & & 0.420 & & 0.57065 & \\
\hline P-16 & 0.460 & & 0.283 & & 0.61522 & \\
\hline P-17 & 0.844 & & 0.519 & & 0.61493 & \\
\hline P-18 & 0.790 & & 0.486 & & 0.61519 & \\
\hline P-19 & 0.439 & & 0.270 & & 0.61503 & \\
\hline P-20 & 0.566 & & 0.348 & & 0.61484 & \\
\hline P-21 & 0.809 & & 0.461 & & 0.56984 & \\
\hline P-22 & 0.784 & & 0.467 & & 0.59566 & \\
\hline P-23 & 1 & & 0.615 & & 0.61500 & \\
\hline S-1 & 0.355 & \multirow{15}{*}{0.522} & 0.355 & \multirow{15}{*}{0.421} & 1 & \multirow{15}{*}{1} \\
\hline S-2 & 0.340 & & 0.340 & & 1 & \\
\hline S-3 & 0.408 & & 0.408 & & 1 & \\
\hline S-4 & 0.335 & & 0.335 & & 1 & \\
\hline S-5 & 0.421 & & 0.421 & & 1 & \\
\hline S-6 & 0.535 & & 0.535 & & 1 & \\
\hline S-7 & 0.702 & & 0.702 & & 1 & \\
\hline S-8 & 0.414 & & 0.414 & & 1 & \\
\hline S-9 & 0.355 & & 0.355 & & 1 & \\
\hline S-10 & 0.429 & & 0.429 & & 1 & \\
\hline S-11 & 0.412 & & 0.412 & & 1 & \\
\hline S-12 & 1 & & 1 & & 1 & \\
\hline S-13 & 1 & & 1 & & 1 & \\
\hline aS-14 & 0.354 & & 0.354 & & 1 & \\
\hline S-15 & 0.763 & & 0.763 & & 1 & \\
\hline H-1 & 0.974 & \multirow{19}{*}{0.698} & 0.385 & & 0.39528 & \multirow{19}{*}{0.63398} \\
\hline H-2 & 0.523 & & 0.424 & & 0.81071 & \\
\hline H-3 & 0.665 & & 0.366 & & 0.55038 & \\
\hline H-4 & 1 & & 0.363 & & 0.36300 & \\
\hline H-5 & 0.565 & & 0.458 & & 0.81062 & \\
\hline H-6 & 0.701 & & 0.378 & & 0.53923 & \\
\hline H-7 & 0.670 & & 0.524 & & 0.78209 & \\
\hline H-8 & 0.732 & & 0.393 & & 0.53689 & \\
\hline H-9 & 0.494 & & 0.381 & & 0.77126 & \\
\hline H-10 & 0.722 & & 0.414 & & 0.57341 & \\
\hline H-11 & 0.558 & & 0.453 & & 0.81183 & \\
\hline H-12 & 0.474 & & 0.268 & & 0.56540 & \\
\hline H-13 & 0.721 & & 0.545 & & 0.75589 & \\
\hline H-14 & 0.655 & & 0.419 & & 0.63969 & \\
\hline H-15 & 0.741 & & 0.416 & & 0.56140 & \\
\hline H-16 & 0.739 & & 0.572 & & 0.77402 & \\
\hline H-17 & 0.890 & & 0.511 & & 0.57416 & \\
\hline H-18 & 1 & & 0.811 & & 0.81100 & \\
\hline H-19 & 0.429 & & 0.319 & & 0.74359 & \\
\hline
\end{tabular}

\section{References}

1. Battese, G.E.; Rao, D.S.P. Technology Gap, Efficiency, and a Stochastic Meta-frontier Function. Int. J. Bus. Econ. 2002, 1, 87-93. 
2. O'Donnell, C.J.; Rao, D.S.P.; Battese, G.E. Meta-frontier Frameworks for the Study of Firm-level Efficiencies and Technology Ratios. Empir. Econ. 2008, 34, 231-255. [CrossRef]

3. Battese, G.E.; Rao, D.S.P.; O'Donnell, C.J. A Meta-frontier Production Function for Estimation of Technical Efficiencies and Technology Gaps for Firms Operating under Different Technologies. J. Product. Anal. 2004, 21,91-103. [CrossRef]

4. Woo, S.-H.; Lai, P.-L.; Chen, Y.-H.; Yang, C.-C. Meta-frontier function approach to operational efficiency for shipping companies. Marit. Policy Manag. 2019, 46, 529-544. [CrossRef]

5. Chung, C.C.; Hwang, C.C. Analysis on Vessel Registration and Operational Performance of Bulk Shipping Firms. Proc. East. Asia Soc. Transp. Stud. 2005, 5, 631-646.

6. Huang, E.W.; Chao, S.L.; Chang, C.C. Assessment of Differences in Efficiency across Strategic Groups in the Container Shipping Context: A Data Envelopment Analysis. J. Shipp. Transp. Logist. 2017, 9, 651-672. [CrossRef]

7. Gong, X.; $\mathrm{Wu}, \mathrm{X}$; Luo, M. Company performance and environmental efficiency: A case study for shipping enterprises. Transp. Policy 2019, 82, 96-106. [CrossRef]

8. Tone, K.; Tsutsui, M. Dynamic DEA with network structure: A slacks-based measure approach. Omega 2014, 42, 124-131. [CrossRef]

9. Lee, H.-S.; Yeh, C.-H. A Multiple Criteria Decision Making Model Based on Fuzzy Multiple Objective DEA. Comput. Vis. 2006, 4252, 917-921.

10. Saeedi, H.; Behdani, B.; Wiegmans, B.; Zuidwijk, R. Assessing the technical efficiency of intermodal freight transport chains using a modified network DEA approach. Transp. Res. Part E Logist. Transp. Rev. 2019, 126, 66-86. [CrossRef]

11. Hwang, C.C.; Chung, C.C. Application of DEA to the Evaluation of the Operational Performance of Bulk Shipping Firms. J. Chin. Inst. Transp. 2004, 16, 145-182.

12. Wu, L.; Pan, K.; Wang, S.; Yang, D. Bulk ship scheduling in industrial shipping with stochastic backhaul canvassing demand. Transp. Res. Part B Methodol. 2018, 117, 117-136. [CrossRef]

13. Abdul Rahman, N.S.F.; Othman, M.K.; Sanusi, I.A.; Arof, A.M.; Ismail, A. Evaluation of Delay Factors on Dry Bulk Cargo Operation in Malaysia: A Case Study of Kemaman Port. Asian J. Shipp. Logist. 2019, 35, 127-137. [CrossRef]

14. Lin, D.-Y.; Liu, H.-Y. Combined ship allocation, routing and freight assignment in tramp shipping. Transp. Res. Part E Logist. Transp. Rev. 2011, 47, 414-431. [CrossRef]

15. Panayides, P.M.; Lambertides, N.; Savva, C.S. The relative efficiency of shipping companies. Transp. Res. Part E Logist. Transp. Rev. 2011, 47, 681-694. [CrossRef]

16. Chen, C.; Chiang, Z.; Hsieh, M.; Zeng, X. Applying the Data Envelopment Analysis to Discuss Performance Evaluation of Customer Relationship Management in Shipping Industry. J. Coast. Res. 2018, 83, 833-838. [CrossRef]

17. Zahran, S.Z.; Bin Alam, J.; Al-Zahrani, A.H.; Smirlis, Y.; Papadimitriou, S.; Tsioumas, V. Analysis of port authority efficiency using data envelopment analysis. Marit. Econ. Logist. 2017, 19, 518-537. [CrossRef]

18. Venturini, G.; Iris, C.; Kontovas, C.A.; Larsen, A. The multi-port berth allocation problem with speed optimization and emission considerations. Transp. Res. Part D Transp. Environ. 2017, 54, 142-159. [CrossRef]

19. Charnes, A.; Cooper, W.; Rhodes, E. Measuring the efficiency of decision making units. Eur. J. Oper. Res. 1978, 2, 429-444. [CrossRef]

20. Färe, R.; Grosskopf, S.; Logan, J.; Lovell, C.A.K. Measuring Efficiency in Production: With an Application to Electric Utilities. In Managerial Issues in Productivity Analysis; Springer: Berlin/Heidelberg, Germany, 1985.

21. Unsal, O.; Oguz, C. An exact algorithm for integrated planning of operations in dry bulk terminals. Transp. Res. Part E Logist. Transp. Rev. 2019, 126, 103-121. [CrossRef]

22. Iris, C.; Pacino, D.; Ropke, S. Improved Formulations and an Adaptive Large Neighborhood Search Heuristic for the Integrated Berth Allocation and Quay Crane Assignment Problem. Transp. Res. Part E 2017, 105, 123-147. [CrossRef]

(C) 2020 by the authors. Licensee MDPI, Basel, Switzerland. This article is an open access article distributed under the terms and conditions of the Creative Commons Attribution (CC BY) license (http://creativecommons.org/licenses/by/4.0/). 